\title{
CorposMídia: juventude, arte e política
}

\section{Denise ESPÍRITO SANTO ${ }^{l}$}

\section{Resumo}

O movimento Ocupa São Paulo de 2015, que em 2016 se reencenou em muitas capitais do país em diferentes espaços públicos, procurou responder através de um estado contínuo de pulsão e de enfrentamentos com a ordem pública e o "poder soberano" a que esta alude (aqui representado muitas vezes pelo aparelho repressor do estado), às muitas intervenções de cunho autoritário que se tem assistido nestes tempos de anomalia social e colapso das instituições públicas do país. A fúria dionisíaca que revolve o chão da escola e dinamiza novos espaços de ensino e de aprendizagem, 52 ajuda a construir não somente os relatos acerca do que representa hoje pertencer/ser pertencido ao mundo da pólis/política, mas sugere igualmente uma nova episteme para aquilo que sustém ou sustenta os campos da ação social, da formação humana e da própria ideia de democracia ou comunidade. As ocupações estudantis contribuem para pensarmos quais políticas os sujeitos precários, tal como anuncia Rancière, são possíveis de arquitetar em contextos de deterioração e liquidação dos atuais modelos de representação política, fato que se estende a quase todas as democracias do planeta. Estaríamos acompanhando numa perspectiva muito otimista, uma abertura humana para o plano de uma nova política - a das micropolíticas? A crise política (mais que econômica a meu ver) que vivemos hoje no Brasil e que expõe sucessivas violações ao estado de direito e de bem estar social, nos exige pensar ações e estratégias de resistência e resiliência para o devir nação, para o devir estado, para o devir comunidade que estão ainda por se desenhar emmeio ao caos e sob os escombros do que restará da própria ideia de república ou democracia. Será por essa razão que devemos explorar neste artigo o protagonismo juvenil como um dos mais importantes episódios da história recente do país e face aos transbordamentos estéticos que emanam da escola, pensar as relações entre corpos, mídia, juventude, arte, política e performance social.

\section{Summary}

The "Ocupa São Paulo" movement of 2015, which was reenacted in different public spaces of many Brazilian cities during 2016, sought to respond - by means of a continuous state of drive and confrontations - to the public order and the "sovereign power" that public order alludes to (often represented here by the repressive apparatus of the state) and to the many authoritarian interventions that have been witnessed in these times of social anomaly and collapse of the country's public institutions. The Dionysian fury which makes the ground of the school system shake and invigorates new spaces of teaching and learning, helps to build not only the accounts of what represents today's belonging to/to be belonged by the world of polis/politics, but also suggests a new episteme for that which sustains or supports the fields of social action, human formation and the very idea of democracy or community. Student occupations help us reflect on the politics that these precarious subjects - as announced by Rancière - would be able to conceive, in these contexts of deterioration and liquidation of the current models of political representation - a phenomenon that extendstoalmostallthedemocraciesoftheplanet.Arewefollowingatoooptimisticperspective, that of a human opening to a new idea of politics - that of micropolitics? The political crisis (more than the economic one, in my view) under which we are living in Brazil today, exposes successive violations of the rule of law and social welfare, requiring us to think of actions and strategies of resistance and resilience for the becoming of the nation, the becoming of the state, the becoming of the community that are yet to be drawn amid the chaos and under the rubble of what will remain of the very idea of republic or democracy. Maybe that is the reason why we should explore in this article the role of youth as a protagonist in one of the most important episodes in the country's recent history and in face of the aesthetic overflows which emanate from the school, and to think about the relationships between bodies, media, youth, art, politics and socialperformance.

\section{Résumé}

Occupy São Paulo mouvement de 2015, qui en 2016 a été à nouveau mis en scène dans de nombreuses villes du pays dans différents espaces publics, a cherché à répondre par un état continu d'entraînement et de confrontations avec l'ordre

\footnotetext{
${ }^{1}$ Professora do Instituto de Artes da UERJ e doPrograma de Pós-graduação em Arte e Cultura Contemporânea PPGArtes Professora Procientista da UERJ. Visiting Scholar at NYU 2016. E-mail: deniseespirito@ gmail.com
} 
public et le «pouvoir souverain » qu'il fait référence ( représentée ici souvent par l'appareil répressif de l'État), le nombre des interventions autoritarisme qui ont été faites par ces temps d'anomalies sociales et l'effondrement des institutions publiques. La fureur dionysiaque tournant le sol de l'école et rationalise nouveaux espaces d'apprentissage et d'apprentissage, aide à construire non seulement les rapports de ce qui est aujourd'hui appartiennent / être appartenu au monde des politiques / polis, mais suggère également une nouvelle épistémè que qui soutient ou soutient les domaines de l'action sociale, la formation humaine et l'idée de la démocratie ou de la communauté. Les occupations étudiantes contribuent à penser au sujet des politiques précaires qui, comme annoncé Rancière, sont possibles pour concevoir des contextes et la détérioration règlement des modèles actuels de représentation politique, un fait qui s'étend à presque toutes les démocraties du monde. Nous suivrons une perspective très optimiste, une ouverture humaine au plan d'une nouvelle politique - du micro? La crise politique (plus économique à mon avis) que nous vivons aujourd'hui au Brésil et en exposant les violations successives de l'état de droit et la protection sociale, exige une réflexion sur les actions et les stratégies de résistance et de résilience pour devenir la nation à devenir État, pour devenir la communauté qui sont encore ${ }^{53}$ à tirer dans le chaos et sous les décombres de ce qui restede l'idée même de la démocratie ou de la république. Ce sera pour cette raison que nous explorons dans cet article la participation des jeunes comme l'un des épisodes les plus importants de l'histoire récente du pays et répondre aux retombées esthétiques émanant de l'école, pensant que la relation entre les organismes, les médias, la jeunesse, l'art, la politique et la performancesociale.

CorposMídia, cité, performance, Occupation 
“eu vou no bloco é desta mocidade,
que não está na saudade e constrói a manhã desejada...”

Gonzaguinha

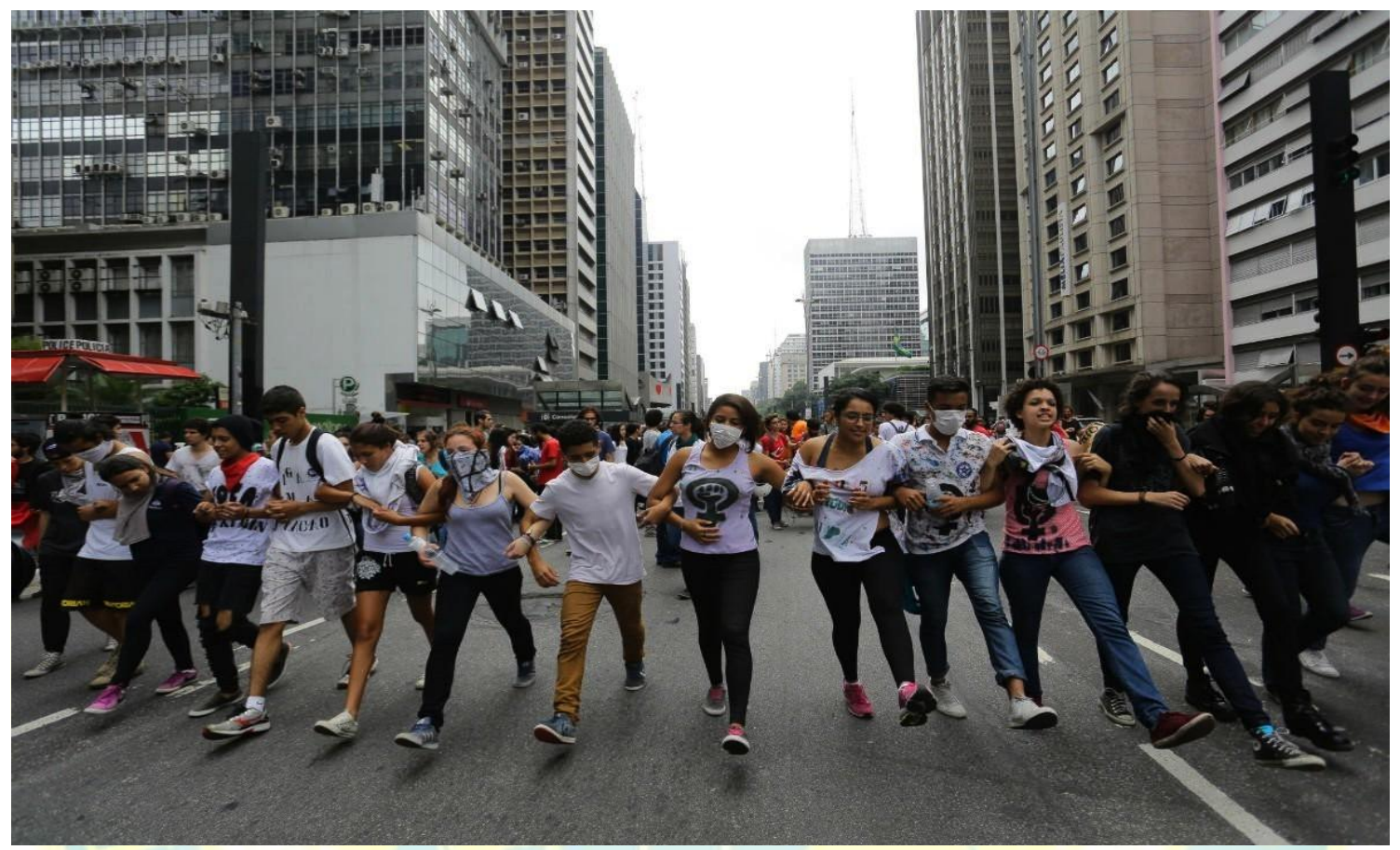

Movimento Ocupa São Paulo, 2015

Fonte: Jornalistas Livres

Caso nos fosse pedido destacar um acontecimento dos mais potentes a relacionar juventude e cidade nos últimos 3 anos no Brasil, eu diria sem duvidar que tratou-se dos quase sessenta dias em que os estudantes secundaristas de São Paulo mantiveram-se entrincheirados nas duzentas escolas ocupadas em oposição ao decreto de "reorganização" do governo de Geraldo Alckmin ${ }^{2}$. Esta proposta tinha a época o objetivo de implementar um programa por segmentação dos ciclos escolares que redundaria na movimentação de muitos destes jovens por outros bairros e localidades,

\footnotetext{
${ }^{2}$ Inicialmente divulgado como um projeto de reorganização do sistema escolar do estado de São Paulo, mais especificamente, visando implementar uma proposta de segmentação por ciclos, o projeto na verdade correspondiaa outros interesses mais escusos, um dos quais reacomodar um expressivo contingente de estudantes em turmas superlotadas visando com isso reduzir o número de algumas escolas em distintas áreas da cidade. A proposta do governo Alckmin não tardou a mostrar-se extremamente duvidosa, por abrigar-se numa jogada que envolvia interesses dos setores imobiliários em "suspeitas transações" com o governo, no sentido de desapropriação de escolas em terrenos nobres da cidade para fins de especulação, além é claro de uma jogada que compreendia a desoneração do orçamento do estado e enxugamento da máquina pública. A resposta ao projeto acionou uma mobilização inédita de alunxs e professorxs contra sua implementação e o que reverberava para toda a comunidade escolar era a total inexistência de diálogo com os conselhos educativos, os estudantes, os docentes e a comunidade.
} 
umavezqueprevia-seoencerramentodasatividadesdecercade200escolasemdistintasáreasdacidade. que estava por detrás desta inciativa no mínimo duvidosa, não era propriamente um plano de reformulação educacional, mas o metódico avanço de uma política de estado que vem designando as áreas da educação e da saúde como alvos de um projeto de desoneração orçamentária, terceirização e enxugamento da máquinapública.

No entanto, no decorrer dos preparativos que anunciaram essa "reorganização" algumas denúncias graves contra a base governista do governador Geraldo Alckmin e seu partido (PSDB) chegaram ao conhecimento da população, temperando com intrépida ousadia as ações estudantis que redundaram no Movimento Ocupa São Paulo de 2015; episódios como o desvio da merenda ${ }^{3}$ por um ex-secretário de governo e as fraudulentas parcerias com setores imobiliários que desejavam (ainda desejam) utilizar os terrenos de escolas públicas localizadas em regiões nobres da cidade, afim de viabilizar empreendimentos privados que reforçariam o que hoje discutimos como o resultado das alianças entre o capital financista e as políticas públicas para a cidade, que nas palavras do geógrafo britânico David Harvey ${ }^{4}$ confirmariam o status de "cidadecommodities".

A “cidade commodities" seria a meu ver a forma contemporânea de se viabilizar projetos urbanísticos que operam políticas públicas vinculadas aos interesses privados no que concerne às cidades e sua respectiva modernização; desde o início do século XX no Brasil, a ideia de cidade e modernização seguiu amparada por projetos que tinham por fim reforçar um imaginário cosmopolita, de metrópole moderna, sendo em sua quase totalidade inspirados nas experiências européias ${ }^{5}$ e portanto, inscritas no âmbito de uma lógica que aprofundaria a gentrificação e o

\begin{abstract}
${ }^{3}$ Destaco os links abaixo para o conhecimento detalhado de algumas destas denúncias e dos poucos resultados obtidos até o momento pelo Ministério Público e demais instituições que deveriam zelar pelo combate à corrupção no governo do estado de São Paulo: "A CPI da Merenda é uma farsa e você precisa saber o porque" acessado em 16/09/2016 ninja.oximity.com; "Investigados dizem que Capez ganhou propina em fraude de merenda em SP" acessado em 03/10/2016; "Cheque mostra pagamento de cooperativa a assessor de Capez" acessado em03/10/2016http://g1.globo.com/sao-paulo/noticia/2016/01/investigados-dizem-que-capez-ganhou-propina-emfraude-da- merenda-em-sp.html;http://g1.globo.com/sao-paulo/noticia/2016/08/cheque-mostra-pagamento-decooperativa- assessor-de-capez.html; "CPI da Merenda volta do recesso e não convoca Capez" acessado em 03/10/2016 http://g1.globo.com/sao-paulo/noticia/2016/08/cpi-da-merenda-volta-do-recesso-e-nao-convoca-capez.html
\end{abstract}

\footnotetext{
${ }^{4}$ Ver a esse respeito a jornada de estudos e debates sobre direitos humanos e o direito à cidade, promovida pelo deputado Marcelo Freixo (PSOL) e o geógrafo britânico David Harvey ao longo de 2015 e a publicação intitulada "Cidades rebeldes" (Carta Maior/BoiTempo Editorial, 2013), que reúne artigos diversos sobre o Movimento Passe Livre, de 2013.

${ }^{5}$ Ver a esse respeito o vasto repertório de estudos sobre o "Bota Abaixo", programa de reformas urbanísticas promovidas pelo prefeito Pereira Passos no início do século XX no Rio de Janeiro. Inspirado pelas transformações urbanísticas de Haussman de Paris, o "Bota Abaixo" promoveu o maior e mais impactante programa de reformas urbanas que prometiam a modernização da cidade, com alto custo para as populações mais pobres que sofreramcom as desocupações emmassa.
} 
racismo ambiental ${ }^{6}$.

A cidade é o ponto de partida para pensarmos os indícios tanto do que serviriaaum projeto subserviente ao capital transnacional e suas relações promíscuas com o estado, assim como ao embrutecimento das relações comunais através dos modos de encapsulamento dos indivíduos em territórios higienizados e blindados à dinâmica viva das cidades; mas, a cidade também configura o ponto de partida para pensarmos o oposto, neste caso, a emergência de territórios e espaços que representam as formas de resiliência que propagam outros modos de sociabilidade e que 156 desestabilizam as determinações dos que estão "autorizados" a viver, usufruir, deslocar-se nas cidades, a nelas pertencer/ser pertencido ${ }^{7}$.

As imagens que viralizaram nas redes sociais e povoaram boa parte das conversas em sala de aula com nossos estudantes e na companhia de colegas professores, impressionaram não só por sua potência vinculando jovens, quase meninos e meninas, em instantâneos flagrantes de corpos tomados por uma força singular e estranha, eu diria, uma força dionisíaca, mas também revelaram o poder da imagem como simbologia de uma luta que capitaliza de um modo um tanto inédito o ideário da sociedade do espetáculo. Imagem como "tecnologia de poder" que reafirma a sua condição de um dispositivo ${ }^{8}$ e opera uma rede entre corpos, mídia, arte e política; em muitas dessas

${ }^{6}$ Termo em construção, mas que no entanto, aponta para os episódios que cercam as transformações urbanísticas da cidade do Rio de Janeiro no presente em função de eventos internacionais que aprofundam o apartheid social (Fifa 2014 e Olimpíadas 2016), contribuindo em algumas situações para a explosão da violência em áreas periferizadasda cidade. Historicamente, a ideia deste conceito "racismo ambiental", esteve desde sempre ligada às transformações urbanísticas da cidade do Rio de Janeiro que remontam ao início do século XX período em que corresponde ao "Bota Abaixo" do Prefeito Pereira Passos; nesta ocasião, eventos como a abertura da Avenida Central, o desmonte do Morro do Castelo, a abertura das novas conexões viárias para bairros até então distantes do centro da cidade, como Botafogo, Gávea e outros repercutiram no deslocamento das populações mais pobres para regiões que configurariam novos territórios de africanidades ou do emergente operariado carioca; essas localidadesredesenhar os espaços sociais e de intensa produção econômica e cultural da cidade do Rio de Janeiro. No entanto, sou devedora na construção deste conceito "racismo ambiental" à obra do geógrafo brasileiro Milton Santos e às performances urbanas da Cia. Étnica de dança, através de sua diretora e cineasta Carmen Luz

\footnotetext{
${ }^{7}$ Uma nota se faz necessário; a cidade do Rio de Janeiro vive em seus derradeiros dias uma escalada de violência estrategicamente subtraída dos principais noticiários, por ocorrer nas localidades pobres e periferizadas; trata-se do avanço de uma máquina de extermínio promovida pelo estado e sua corporação mais nefasta - a Polícia Militar,sob os olhares atônitos da população carioca e a indiferença de alguns setores da classe média que tem se mostrado extremamente coniventes com o estado de exceção que estamos vivendo atualmente nopaís.
}

\footnotetext{
${ }^{8}$ Ver Agamben "O que é um dispositivo", a partir de Foucault ele afirma: "É um conjunto heterogeneo, que inclui virtualmente qualquer coisa, linguístico e não linguístico no mesmo título: discursos, instituições, edifícios, lei, medidas de segurança, proposições filosóficas... O dispositivo tem sempre uma função estratégica concreta e se inscreve sempre em uma relação de poder... É algo de geral (um reseau, uma "rede") porque inclui em si aepisteme, que para Foucault é aquilo que em uma certa sociedade permite distinguir e que é aceito como um enunciado científico daquilo que não é científico" (AGAMBEN, Giorgio. O que é o contemporâneo e outros ensaios. Santa Catarina: Argos, 2009, p.9)
} 
imagens, a presença de corpos juvenis sob o enquadramento dos símbolos que configuram a violência do Estado: botinas, cassetetes, capacetes, escudos e a poeira cósmica das bombas de gás lacrimogênio disparadas para dissolver as multidões, tudo o que nos lembraria, entre um sentimento confuso de tristeza e alegria, de Maio de 68 na França, da Passeata dos 100 mil em plena ditadura militar no Brasil e de outros episódios mais recentes - o levante dos estudantes na Praça da Paz Celestial em 1989, em Pequim; a Praça Tahir no Egito durante a Primavera Árabe em 2011; a Praça Maidan em Kiev em 2014; as manifestações de junho no Brasil de 2013 e mais recentemente, os protestos contra o Golpe geopolítico-parlamentar-jurídico-midiático-empresarial no Brasil em 2016.O efeito das ocupações de São Paulo em novembro de 2015 causou uma tsunami na opinião ${ }^{9}$ pública de um modo geral, mas produziu uma perplexidade maior entre os professores porque desmontava uma tese há muito discutida e quase lugar comum - sobre a condição de uma escola apartada dos interesses de seus estudantes e dos efeitos disto para o fracasso escolar.

Sob o argumento de que o sistema público escolar, tal como o vemos atualmente, reproduz os mecanismos de exclusão social sendo considerado ineficaz para acompanhar tanto os desafios de uma educação contemporânea ${ }^{10}$, quanto o de proporcionar uma base curricular mínima a todos os estudantes de diferentes regiões do país ${ }^{11}$, tais argumentos poderiam ser facilmente desmontados a partir de um rápido olhar sobre algumas propostas que emergiram do Movimento Ocupa São Paulo. Por sua vez, merece atenção a reverberação do movimento junto à opinião pública, num primeiro momento favorável às Ocupações e a participação inconteste de uma legião de professores de distintas áreas que vieram somar ao movimento; com isso, foi possível acompanhar desde as "aulas públicas" e seminários abordando distintos temas, alguns dos quais ausentes dos currículos escolares, à realização de ações performativas durante as manifestações que tomaram as ruas da

\footnotetext{
${ }^{9}$ Entre dezembro de 2015 a março 2016, cerca de 900 ficaram ocupadas em todo o Brasil pelos estudantes secundaristas que se posicionam contra a Medida Provisória PEC 241; esta PEC aprovada recentemente congelouos investimentos públicos na área da saúde e da educação pelos próximos 20 anos, medida inconstitucional que agrava o quadro de violações contra a Constituição Brasileira de 1988, que vem sendo implementada pelo atual governo golpista.
}

\begin{abstract}
${ }^{10}$ Dito assim de forma genérica, os desafios da educação contemporânea deveriam ser analisados sob o prisma de muitas variantes, dentre as quais eu destacaria inicialmente o colapso de um determinado modelo de ensino e de produção do conhecimento amparado pelas "grandes narrativas históricas", modelo este que colide com os modosde pensamento, produção e disseminação dos saberes num cenário de alta tecnologia e de realidade virtual, de pós- humanismo, ciborguianismo e outros "ismos" que constituem a nova ordem mundial. Por outro lado, há que se observar as relações entre o colapso deste modelo escolar em direta sinergia com as crises sistêmicas do capitalismo global e do avanço do que haveria de pior e mais conservador neste projeto neoliberal que atinge violenta e despudoradamente as jovens e débeis democracias do bloco sul-americano, dentre as quais eu destacaria aqui Brasil, Argentina, Peru eColômbia.
\end{abstract}

\footnotetext{
${ }^{11}$ Temos que considerar nesta brevíssima análise a extensão do sistema público educacional que é responsável por cerca de 95\% das matrículas de crianças e jovens em idade escolar, tornando complexas as relações entrecurrículo, formação docente e políticaspublicas.
} 
capital paulista, tema que iremos abordar mais adiante. Com isso, concluímos que há algo maior e estruturalmente complexo que condiciona a crise de quase todos os sistemas escolares do planeta, independente dos padrões econômicos/sociais que sabemos bem, são fatores importantes porém insuficientes para pensarmos o binômio fracasso/sucesso escolar.

O que não conseguíamos entender de imediato com as ocupações de São Paulo seriam os indícios do que estaria ocorrendo nestas movimentações subterrâneas dentro da escola, movimentações sutis e arrebatadoras que germinariam uma vontade incondicional para a abertura de outros modos de pensar e fazer a escola, de fazê-la atravessar e/ou ser atravessada pela pujança de corpos com os quais a escola sempre lutou abertamente e no entanto, sempre foi sacudida por eles. O movimento secundarista de São Paulo sacudiu olhos, corações, línguas, vísceras e ouvidos acostumados aos discursos monocórdios sobre o nosso ambiente escolar; numa outra ponta, o Ocupa Escola escutou e deu forma às vozes das ruas, nos exigindo respostas sobre o que querem os estudantes e o que pode a escola como instituição capaz de responder a essa presença dos sujeitos políticos e das políticas do sujeito em nossa tardiamodernidade.

O que vimos em São Paulo e por extensão o que estamos vendo hoje em diversas capitais do país, nos remete à essas movimentações invisíveis de corpos dionisíacos que, instalados e em pleno processo de centrifugação, foram capazes de produzir um grande debate cujo maior mérito foi recolocar em pauta a escola, essa instituição secular no país. Numa outra ponta, as ocupações devem nos inspirar - professores, estudantes, gestores, pesquisadores e sociedade, sobre qual escola deverá emergir a partir deste movimento estudantil e os efeitos disto tudo sobre a educação de um modo geral, aí incluindo o sistema privado que apático e distante desta convulsão juvenil, permanece em seu isolamento narcísico ou acredita poder ocupar um posto equivalente à discutível promessa de "fomentador das lideranças econômicas". Penso que o "fracasso escolar" tem implicações muito mais complexas, sendo essas da ordem político-econômica-cultural-social em sociedades periféricas como a nossa; no Brasil, especificamente, essas implicações são resultantes do "apartheid social" que pavimenta as grandes desigualdades sociais do país. Eu avançaria um pouco mais ao propor uma discussão sobre o que a escola pública ensina ao sistema privado de ensino e o que este último ganharia caso pudesse acercar-se dos grandes desafios da educação do nosso tempo, pois do contrário pergunto: como sustentar a lira desafinada de um sistema que insiste na partilha injusta e desleal do acesso ao conhecimento, à cidadania, à igualdade social, à liberdade de expressão senão o que no Brasil conhecemos como a súmula da divisão entre a Casa Grande e a Senzala? Enfim, questões que essa linda juventude dionisíaca nos ensinou neste ano de 2015. 
Movimento Ocupa São Paulo, 2015

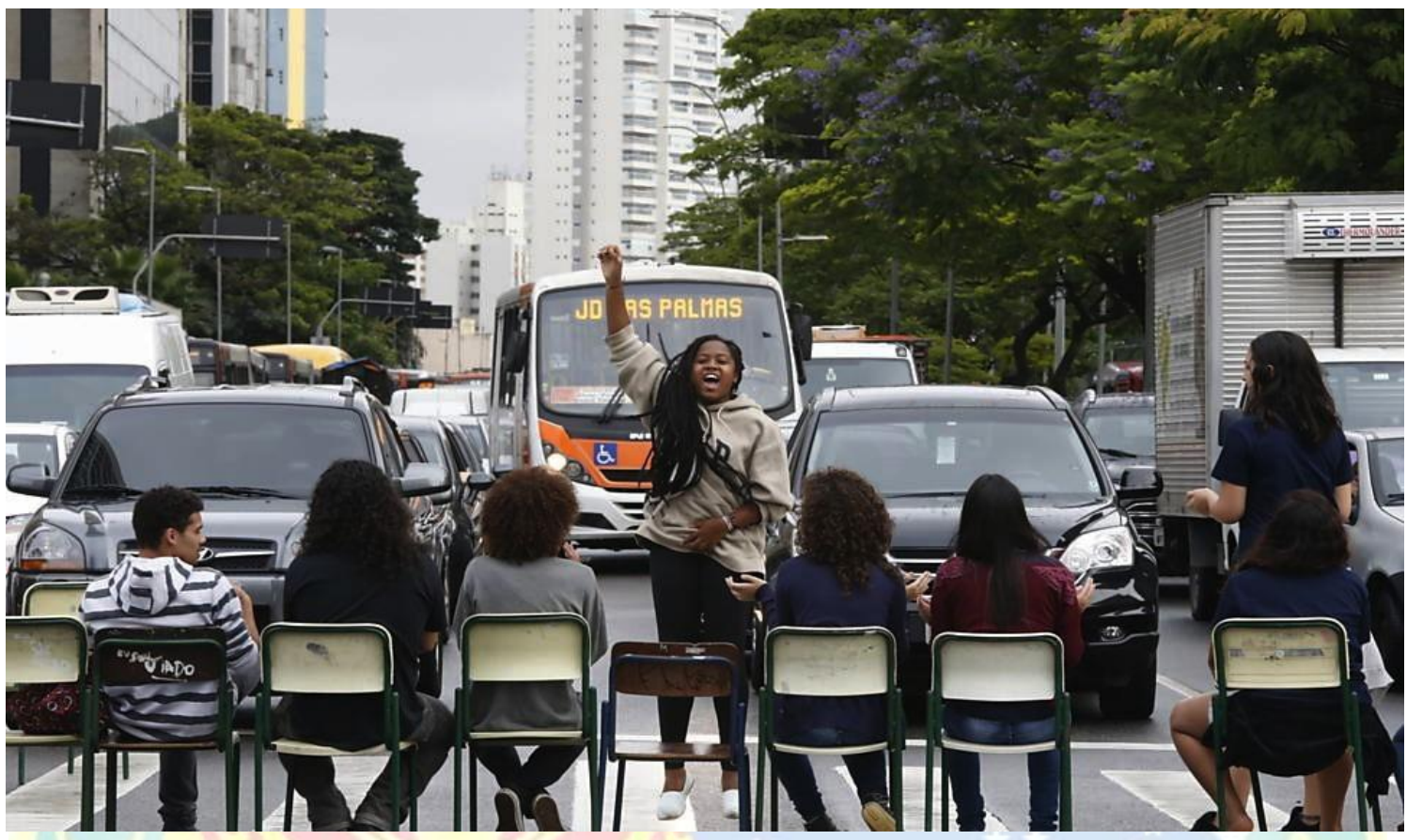

Fonte: Jornalistas Livres

Movimento Ocupa São Paulo, 2015

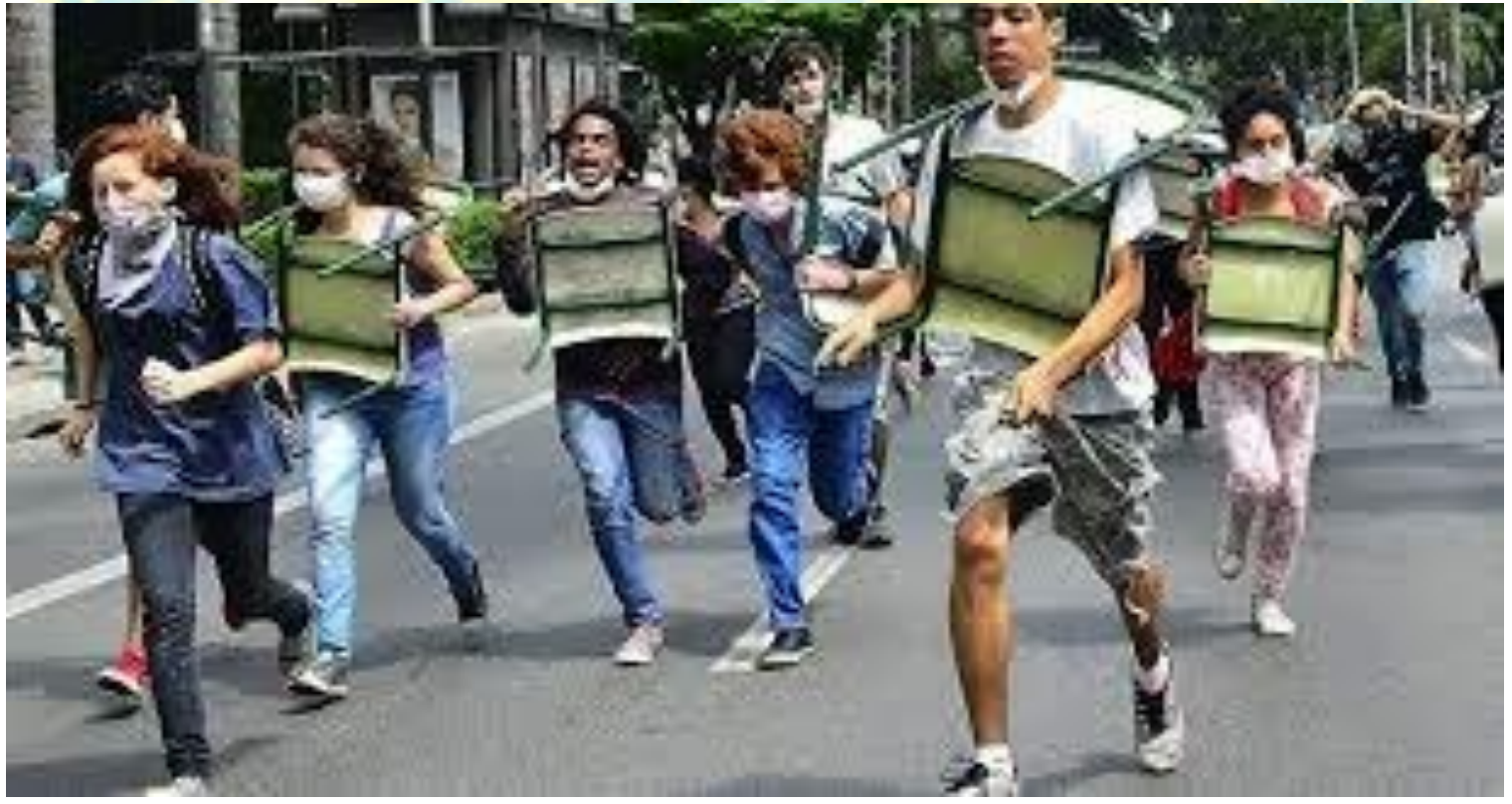

Fonte: Jornalistas Livres 


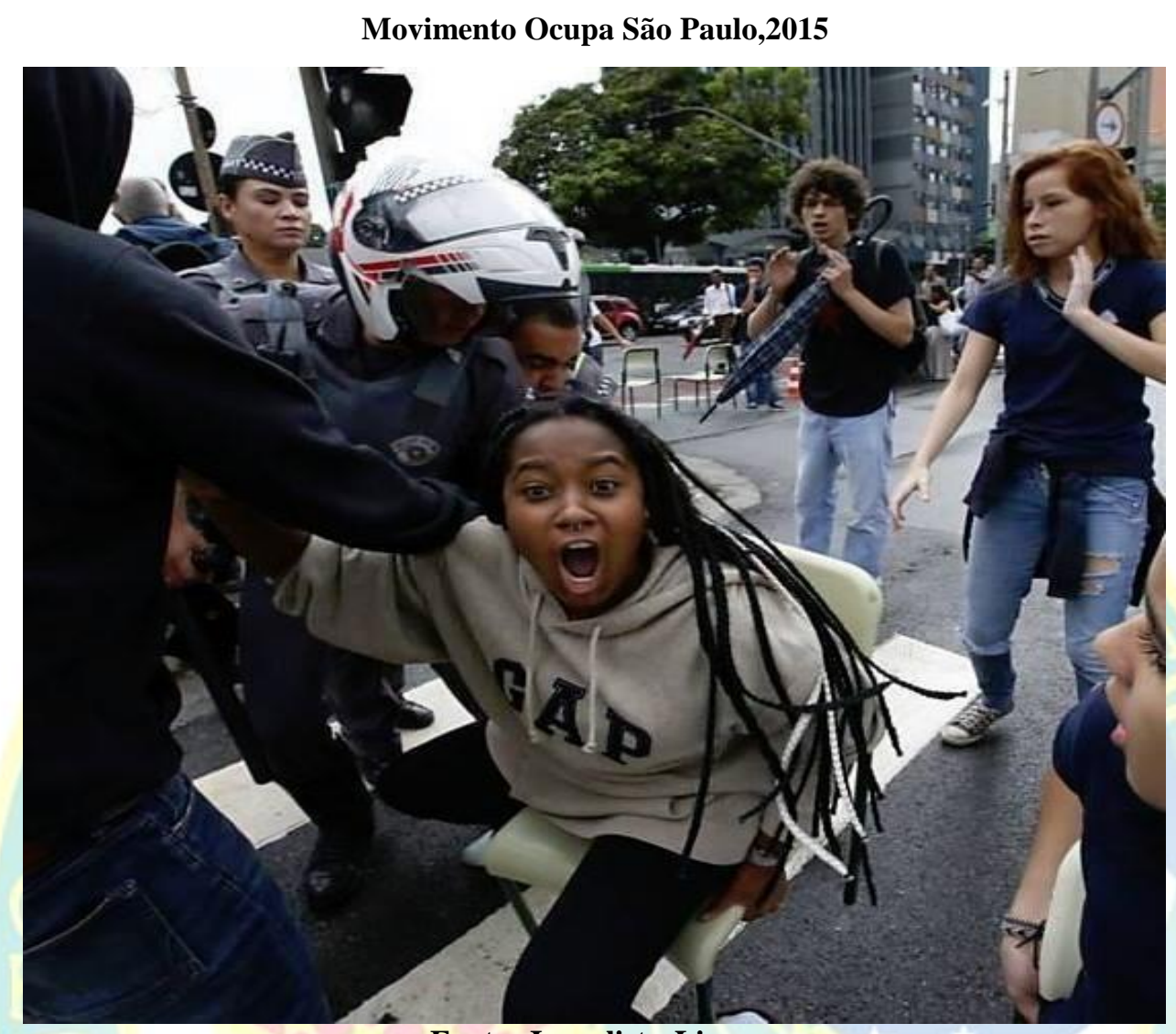

Fonte: JornalistasLivres

Movimento Ocupa São Paulo,2015

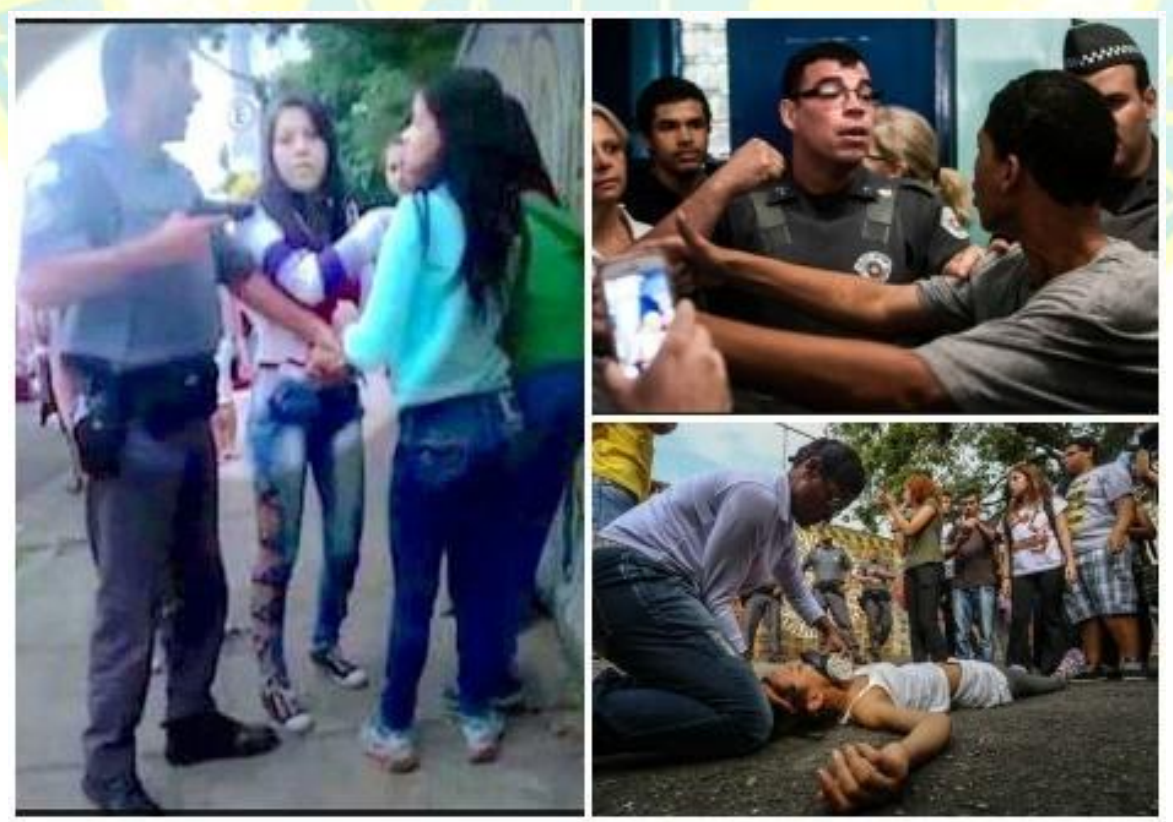

Fonte: Jornalistas Livres 


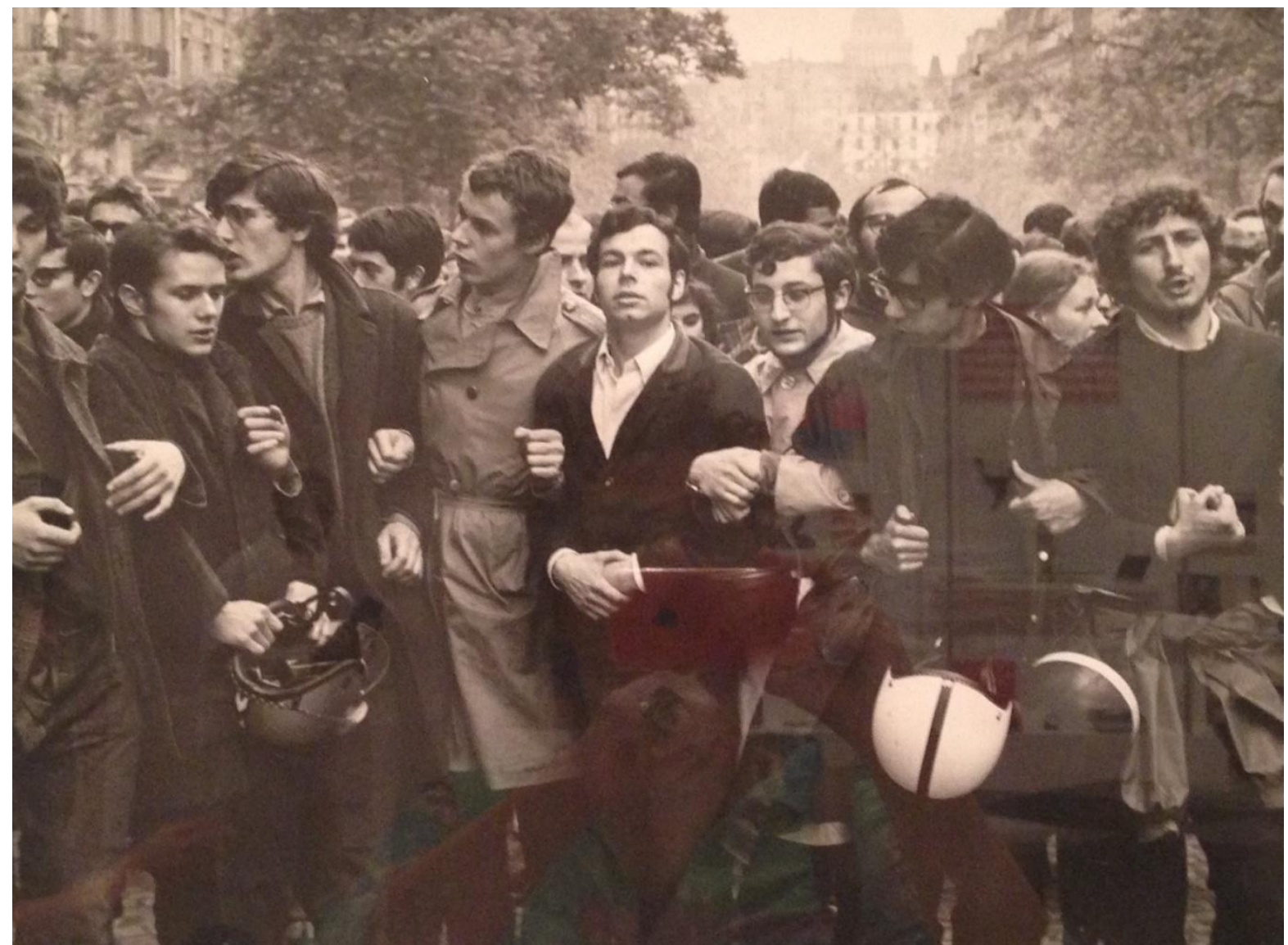

\section{Bruce Corner \\ Maio de 68, Paris \\ MOMA, NY, 2016}

Foi a partir de uma publicação organizada pelo filósofo Emmanuel Alloa (ALLOA, $2015)^{12}$ que ofereceu caminhos para uma articulação com o tema das juventudes dionisíacas, mais especificamente, abrindo uma discussão sobre os significados que envolvem os usos e "abusos" da imagem pelos estudantes secundaristas de São Paulo e de que forma os modos de apropriação da imagem contribuem para pensarmos as novas estratégias políticas em tempos de mídias independentes, de redes sociais e cyberespaço; como através da produção e massiva circulação de imagens das manifestações, marchas, protestos, ocupações que se disseminaram em todo o país desde 2015 e que se intensificam agora com o Golpe de 2016, se tem denunciado as graves violações que vem ocorrendo no Brasil. Apoiando-me em textos publicados nesta antologia que incluem autores como W. J. T. Mitchel, Jacques Rancière, Jean-Luc Nancy, Hans Belting, George

\footnotetext{
${ }^{12}$ Destaco 3 textos que abordam diretamente essa temática: RANCIÈRE, Jacques. As imagens querem realmente viver? ALLOA, Emmanuel. Entre a transparência e a opacidade - o que a imagem dá a pensar; MITCHEL, W J T. O que as imagens realmente querem? In: ALLOA, Emmanuel (Org.) Pensar a imagem. BH: Autêntica Editora,2015
} 
Didi-Huberman, além do próprio Alloa, o objetivo será explorar o estatuto da imagem em nossas sociedades contemporâneas; o que significam as imagens, o que fazem e que tipo de poder elas possuem de afetar o sensível e o cognoscível e de suas implicações para o comportamento humano. Comecemos com a hipótese proposta num dos textos desta antologia ${ }^{12}$ acerca de uma suposta "virada pictórica" (pictorial turn) que teria por fim anunciar o novo estatuto da imagem em nossas sociedadescontemporâneas.

Em realidade, a ideia da "virada pictórica" postula uma espécie de "conquista olímpica" da162 imagem sobre o privilégio da palavra e esta primazia do linguístico em nossas sociedades ocidentais. Pensando esta ordem civilizatória a partir de um marco de ideias e de uma determinada linhagem metafísica, que inclui o primeiro filósofo grego a atribuir à imagem um valor inconsistente devido ao seu pertencimento à ordem das aparências, "as imagens não seriam nada somente simulacros sem vida - e seriam tudo: a realidade da vida alienada..." (RANCIÈRE, 2015), podemos conjecturar sobre o impacto desta virada pictórica para tudo aquilo que reverbera no campo social e simbólico, desde as produções estéticas que contagiam o espectro das lutas sociais e da política. Por outro lado, a "virada pictórica" reflete e ao mesmo tempo está incondicionalmente atada ao esgotamento desta metafísica que outrora sustentou o privilégio da palavra; vem manifestar também o paradoxo de que a imagem corresponderia ao mesmo tempo a "realidade da vida alienada" mas também a consistência do mundo das ligações sociais, para o qual a denúncia sobre a sua inconsistência, por tratar-se de mera aparência, já não seria nada. Não se trata aparentemente de uma substituição da imagem pela palavra ou vice-versa, mesmo porque aprendemos com Foucault que ao fim e ao cabo tudo é discurso - imagens e palavras (assim como toda a rede visível/invisível que constitui algo que nomeamos como linguagem é discurso, exceptuando talvez a linguagem poética que se articula noutras direções, engendrando algo da ordem de uma finalidade sem fim). $\mathrm{O}$ fato novo é que o estatuto da imagem em nossas sociedades contemporâneas demonstraria a visão nihilista do engano de um mundo para o qual "tudo é imagem”, e portanto qualquer denúncia contra a imagem estaria privada de toda e qualquer eficácia. (RANCIÈRE, 2015).

Com isso, defender a "virada pictórica" implica em conceder à imagem não somente uma nova consistência, ou seja, a de reinstaurar o elo das ligações sociais, mas também de contestar o poder desta metafísica que até pouco tempo sustentava, nas palavras de Rancière que "as imagens não seriam nada, apenas simulacros sem vida".

Deste modo, ocorreria com a imagem um fenômeno descrito como a "pensatividade da imagem", nas palavras de Alloa, algo que nos induz a pensar sobre essa dimensão corpórea e quase 
humana da imagem, a superdimensionar o seu estatuto em nossas sociedades contemporâneas. É importanteressaltarqueoqueestáemjogonamaioriadostextosincluídosnestaantologia,seria uma espécie de contestação ou assimilação à categorização proposta inicialmente por Artur Danto sobre “o paradigma duplo da transparência e da opacidade". A proposta de Danto que será amplamente retrabalhada aqui através de algus autores, em especial Alloa, Mitchel e Rancière, contribui com uma crítica à semiologização da imagem e propõe em seu lugar uma aderência à irredutibilidade e inesgotável materialidade da imagem, expondo-a primeira e secundariamente a partir de seu ser 163 bruto.

A imagem sempre esteve no coração do pensamento, fabricando uma espécie de mito sobre o seu poder de transparência e de opacidade e hoje, com a proliferação de dispositivos que disseminam imagens a ponto de afetar o nosso conhecimento do que é real (penso aqui nas Tvs de plasma e a batalha dos pixels para nos fornecer uma imagem que fisiologicamente o olho humano não é capaz de conceber). No entanto, a imagem é tão somente algo que está submetido a uma vontade, neste caso a do sujeito que tem ou acredita ter a consciência de ser o produtor de uma "mensagem". Mas, no que consiste exatamente este "emissor", que tipo de subjetividade se pode atribuir ao sujeito em tempos de consciências evanescentes ou como argumenta Tomás Tadeu que "a subjetividade é, hoje, mais do que nunca, uma construção em ruína” (TADEU, 2009); como propor uma espécie de contra-argumento sobre esse estado de "flotamento" do ser, para quem sabe postularmos o seguinte: o que entendemos por "subjetividade" não anunciaria a falência de algo que está mais para os "universais em ruínas", sendo assim entendido a partir de alguns lugares/conceitos chaves, tais como, a ordem patriarcal, a cultura do capitalismo, a hegemonia do pensamento único isto é, colonial, macho, branco, burguês e heteronormativo? Essas categorias se vêm hoje mais do que nunca confrontadas pelos discursos contra hegemônicos que emergem da lente ampliada de um mundo para o qual deixou de existir a histórica ideia de uma “humanidade"...

Quando aquilo que é supostamente animado se vê profunda e radicalmente afetado, é hora de perguntar: qual é mesmo a natureza daquilo que anima o que é animado? É no confronto com clones, ciborgues e outros híbridos tecnonaturais que a "humanidade" de nossa subjetividade se vê colocada em questão ${ }^{13}$.

A imagem não ambiciona nada a não ser a sua opacidade; mas, a "pensatividade da imagem será portanto, confundida com a pensatividade do sujeito da imagem" (RANCIÈRE, 2015). Se

\footnotetext{
${ }^{13}$ TADEU, Tomás. Nós, ciborgues. O corpo elétrico e a dissolução do humano. In: HARAWAY, Donna,KUNZRU, Hari. Antropologia do ciborgue As vertigens do pós-humano. BH: Autêntica, 2009, páginas9-10. 
condicionamos a imagem como algo que corresponde ao constructo de uma ideia de Ocidente, veremos que o que nos constitui como sujeitos da linguagem remete à imagem e a sua pensatividade. Com isso, ressalto que as movimentações da juventude ao redor do mundo devem ser estudadas como imagem-narrativa que reinstaura uma potência e abre-se para uma importante discussão sobre usos e apropriações da imagem enquanto práticas "contra-pedagógicas": o estudantechinêsdiantedeumafileiradetanquesdeguerranaPraçadaPazCelestialemPequim;a jovem iraniana atingida por um projétil disparado pelas forças de repressão do governo iraniano; os jovens 164 egípcios que ocuparam a Praça Tahir e que resistiram heroicamente ao cerco da polícia durante um dos primeiros episódios que caracterizariam a Primavera Árabe; os estudantes chilenos nas ruas de Santiago lutando pelo sistema público de educação e enfrentando nas ruas a truculência policial; os jovens franceses ateando fogo em carros da polícia e arrastando vidraças nos subúrbios de Paris; os jovens que ocuparam a Praça Maidam em Kiev nas insurreições que deflagraram a sangrenta guerra civil que está acontecendo na Ucrânia; os black blocs nas passeatas de 2013 e neste exato momento, as mulheres (mas também os demais gêneros dissidentes e transgêneros) que protestam nas ruas de Buenos Aires, NY, Rio de Janeiro, São Paulo, Paris, Barcelona contra a cultura do estupro e do feminicídio, assim como os estudantes secundaristas de várias capitais do país que ocuparam suas escolas contra a medida provisória que redundará no colapso de todo sistema público de educação a PEC da morte ou 241. Enfim, inúmeros episódios que aqui poderiam ser invocados para nos fazer lembrar sobre o papel das redes sociais neste cipoal confuso de imagens, textos e interpretações sobre a dimensão global e transnacional de nossos sistemas de comunicação; enfim, muitos acontecimentos que tem virado do avesso as tradicionais formas de protesto, de marchas e manifestações que tomaram conta das ruas e cidades ao redor do globo terrestre ${ }^{14}$.

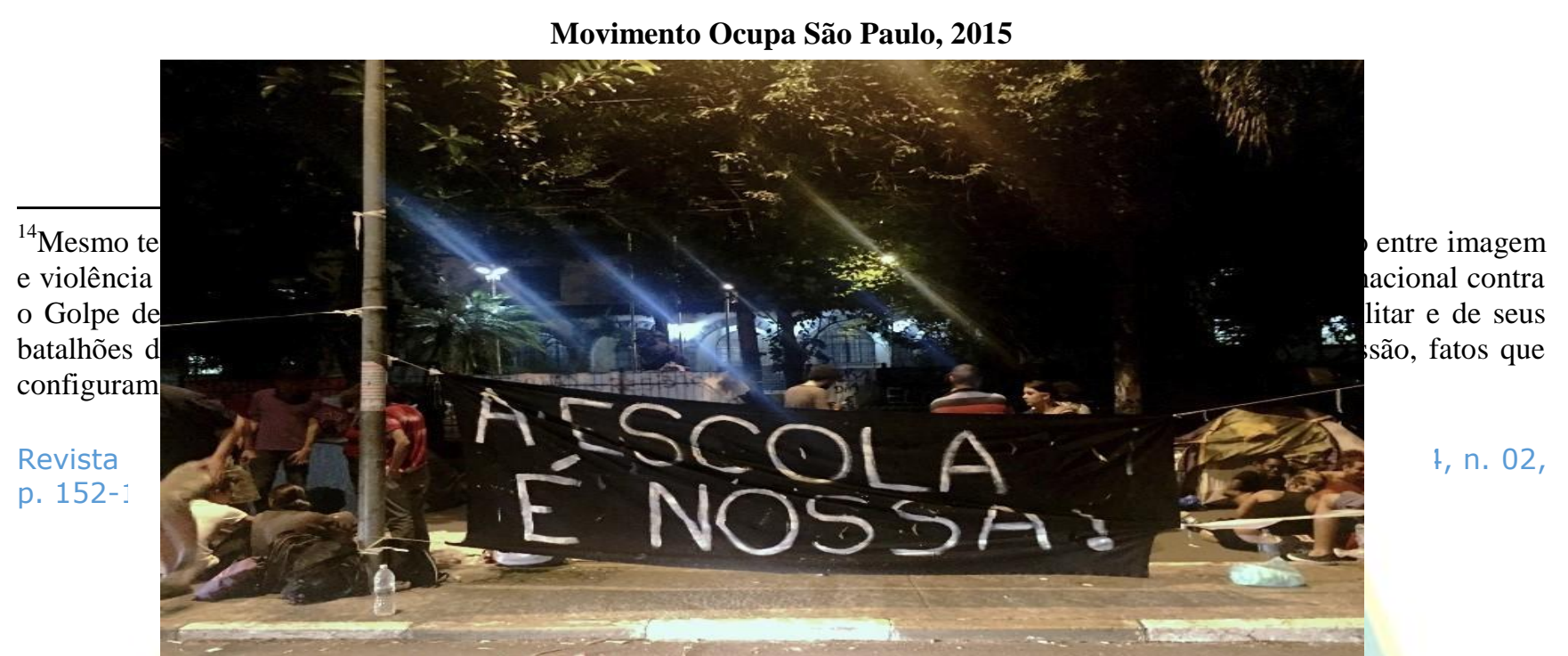


Fonte: Jornalistas Livres

\section{O MESTRE IGNORANTE}

Em um texto instigante sobre os impasses vividos entre "instrução do povo e emancipação intelectual", Jacques Rancière ${ }^{15}$ faz ressalva a uma "excêntrica teoria" de um pouco conhecido Joseph Jacotot que no começo do século XIX afirmava que "um ignorante poderia ensinar a outro ignorante o que ele mesmo desconhecia", promovendo assim a igualdade entre as inteligências. O mestre ignorante, espécie de parábula sobre as condições básicas do ensinar, nos instrui de um modo particular sobre duas questões que considero importantes abordar neste movimento secundarista de São Paulo. De início, constato o efeito das ocupações sobre o território escola como um todo, pensando-o como um território composto por pessoas que ambicionam (de boa fé) coisas semelhantes mas que abriga também muitos enfrentamentos ideológicos (alguns de má-fé). Ampliando um pouco as lentes da observação, penso que as insurreições juvenis impactam enormemente o próprio sistema de governabilidade, especialmente aqueles que comandam de seus gabinetes climatizados e estrategicamente blindados à pulsão dionisíaca dos territórios cotidianos do ambiente escolar, as políticas públicas para a educação. Não à toa, a resposta dada pelos governos contra os estudantes secundaristas em cidades onde estão ocorrendo ocupações e manifestações de rua contra os cortes do orçamento para a educação têm sido uma só - a da repressão e da violência policial através de seus "agentes" públicos. O despreparo da polícia militar tem sido notório e muitas vezes com consequências gravíssimas para a integridade física e psicológica destes jovens, além dos cidadãos que frequentemente participam destas marchas civis. O segundo ponto a destacar seria o protagonismo desta juventude para pensarmos do que se trata "auto-formação" nos campos da política, da estética e do currículo em contextos atuais, assim como o que nos inspiraria a viver e realizar as "comunidades" que vêm a partir da experiência de uma "contra-pedagogia"; contra-pedagogia a alimentar as novas formas de resiliência contra os mecanismos de vigilância e controle cada vez mais sofisticados de nossas sociedades, especialmente quando vivemos sob o jugo de um estado deexceção.

Há que se notar que os modos de praticar, ensinar e promover ações políticas nos territórios

${ }^{15}$ RANCIÈRE, Jacques. O Mestre Ignorante. Belo Horizonte: Autêntica, 2007 
não ortodoxos como será o caso da escola, da rua, dos grêmios (nada que seja absolutamente novo, porém com uma "roupagem" que indiscutivelmente acena para outras formas de organização social e agenciamento no campo das representações sociais) mostrou-nos inúmeros e potentes caminhos para a construção permanente de um processo formativo que tensiona até as últimas consequencias o status quo da escola, dos lugares de fala entre os sujeitos "soberanos" e os sujeitos "efeitos" (recorro aqui a Spivak em texto notável sobre as reverberações do sentimento pós-colonial nas sociedades atuais, o texto citado é "Pode o subalterno falar?"). Finalmente, o que temos visto senão 166 um movimento que nos instrui a pensar, ambicionar e a lutar, por um projeto de escolaexperimental 
como matriz do que deveria ser esta instituição: dinâmica e porosa aos acontecimentos da vida cotidiana $^{16}$.

Atualmente, a discussão sobre o currículo está no centro das principais e maisgraves operações políticas no campo da educação. Não somente o currículo, mas a possibilidade de avanço de um pensamento totalitário, excludente e conservador que inspira a maior parte das discussões sobre a bisonha proposta de reforma do ensino médio comandada pelos incultos burocratas do Ministério da Educação ${ }^{17}$. Será a partir da ideia de currículos que entendemos a importância da arte e de uma linguagem em especial, a performance como arma poética e campo de enfrentamentos contra a ordem pública e o aparato desproporcional da mídia (golpista em geral) oficial. Cumpre dizer que em muitas ações de rua, a alegria exuberante que extravasava das muitas performances que contagiaram a cidade a partir de um modo novo de se organizar, comum a qualquer comuna, mas anunciando talvez o panorama das micropolíticas que configuram novos modos dofazer político com arte que essa juventude explorou em suas intervenções nos espaços públicos dacidade.

\footnotetext{
${ }^{16}$ Não posso deixar de comentar o seguinte: quando estive visitando a Escola Estadual Diadema em dezembro de 2015, exatamente no mesmo dia em que era prevista a realização do "Viradão Cultural" que contou com shows de vários artistas paulistas, me deparei com uma escola limpa e organizada, ocupada por centenas de jovens que se distribuíam em várias tarefas ao longo do dia: desde o preparo das refeições, passando pela limpeza dos espaços coletivos, da segurança - porque era necessário identificar os "autorizados" a entrarem no recinto (eu só pude entrar porque me apresentei como professora da UERJ que estava ali para conhecer o movimento e vivenciar a ocupação diretamente com os principais atores, ou seja, os estudantes); outro ponto que destaco como processoautogestionado de grande inteligência seriam as estratégias da comunicação que incluia definir "quais" informações seriam repassadas à legião de jornalistas que permaneciam "pacientemente" do lado de fora da escola; enfim vivenciei um organismo vivo e potente que me deixou muito feliz e por que não dizer, esperançosa. Voltei para o Rio de Janeiro pensando na importância deste movimento e na história, com $\mathrm{H}$ maiúsculo, que essa juventude está construindo em dias tão terríveis para o nosso país.
}

${ }^{17}$ Anedota de mau gosto? Não, porém o fato é que recentemente o ilegítimo ministro da educação destituiu todo o comando do conselho federal de educação e vem se aproveitando da deriva institucional, do avanço do estado de exceção e das práticas de inconstitucionalidade nos 3 poderes para promover o desmonte daquele que seria considerado um projeto de excelência no âmbito do ensino médio no país, a crição dos Institutos Federais de Educação Tecnológica, com as suas 300 unidades espalhadas por todo o território brasileiro. Isto sem falar em outros projetos bisonhos como o tal do Escola "sem" Partido, de direita e fascista que tem recebido para grandepreocupação de nossa categoria docente, apoio de parlamentares e figuras públicas de baixíssima densidadeintelectual 
Performance social e pedagogia da performance

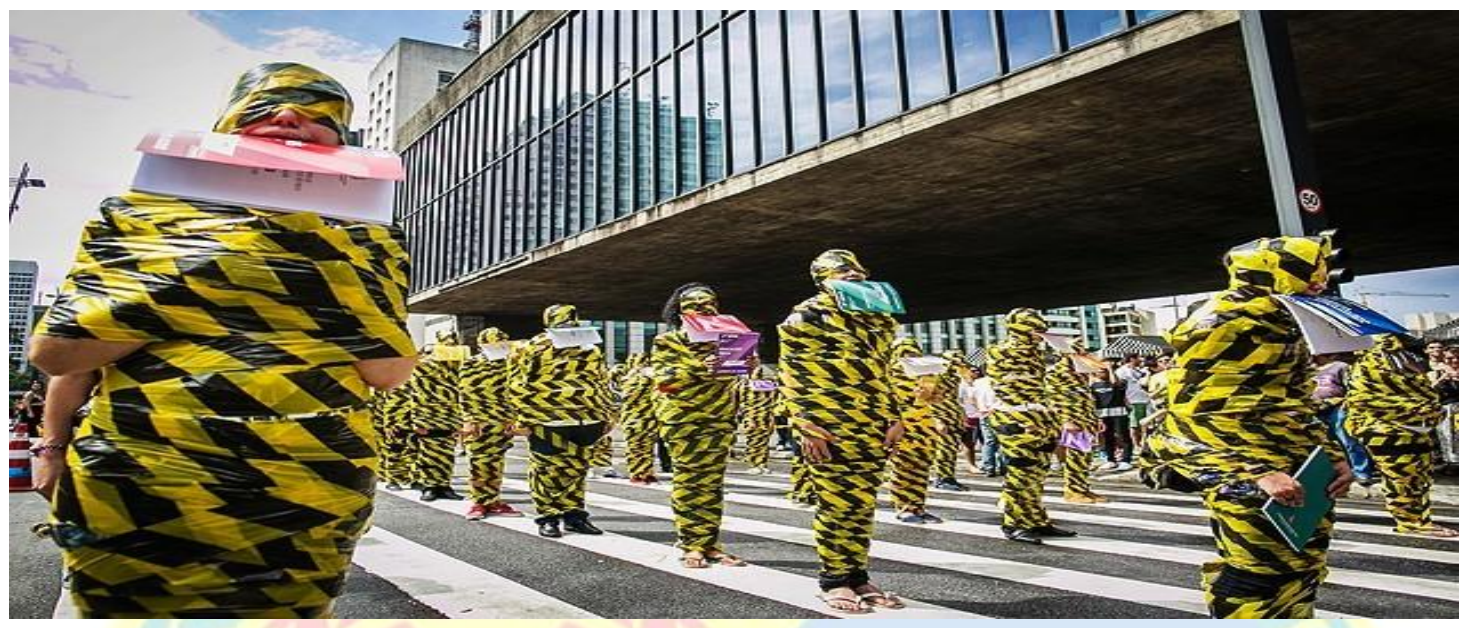

Movimento Ocupa São Paulo, 2015

Fonte: Jornalistas Livres

Inicialmente, gostaria de registrar que a experiência com uma Ocupação sempre nos revela aspectos surpreendentes: desde o fato de reconhecermos que nas muitas escolas ocupadas (algumas delas em que estive presente), o nível de organização, de limpeza, de distribuição de tarefas, de designação de funções, de colaboração, de horizontalidade nas questões de gênero ${ }^{18}$ e outras atividades próprias ao que entendemos por movimentos comunitários, sejam esses estudantis, sociais, sindicais e/outros, indicava um nível de cooperação e de organicidade que tinham por pressuposto a organização do espaço social reforçando a meu ver aquilo que nos parece indissociável de nossa espécie, a humana, mesmo considerando que em condições onde o poder narcísico, a individualidade parecem solapar a possibilidade de vidas em comum.

Num segundo plano, me interessa abordar o quanto esse espanto pela maturidade do movimento e dos estudantes que participaram das ocupações desencadeou em alguns professores, notadamente aqueles professores resistentes a tudo que desestabiliza e deshierarquiza, uma resistência e em alguns casos uma desproporcional afetação que na realidade revelava um tipo de insegurança muito comum para todos nós praticantes do magistério, mas que ganhava outros contornos quanto aos "efeitos" das ocupações sobre o cotidiano escolar, isto é, a preocupação com a "disciplina" e "interesse pelas aulas", agora mais do que nunca afetados pela indisfarçavel percepção da crise de todo sistema escolar e mais especificamente do colapso de uma ideia de currículo que teima em excluir peremptoriamente do debate o seu principal ator - o estudante. Em muitas ocupações e isto pude constatar pessoalmente, um novo currículo desenhava-se coma

\footnotetext{
${ }^{18}$ Ver a esse respeito um documentário "Lute como uma menina”, de Flávio Colombini e Beatriz Alonso, 2015. 
participação coletiva e decisões tomadas em assembléias que traziam para o centro da roda temas e discussões que embora presentes no cotidiano escolar, quase nunca são absorvidos e/ou apropriados cotidianamente, tais como discussões de gênero, sexualidade, sobre cidadania e consumo, sobre arte, política e estética, sobre racismo e o genocídio das populações afrodescendentes no Brasil, que configuravam novos cenários pelos quais aqueles meninos e meninas aspiravam ingressar; com isso, a produção de conhecimentos através da estreita colaboração com professores, universitários, movimentos sociais, lideranças comunitárias, afinou o desejo de se construir uma escola comum acolhedora, onde o aprender/ensinar passava por critérios muito mais "desejantes" que autocráticos, potencializando assim o que desde Paulo Freire entendemos como pedagogia da autonomia, que visa superar o conceito de pedagogia embrutecedora em que uns estão autorizados a ensinar (o sujeito soberano) e outros a aprender (o sujeitoefeito).

Portanto, é a partir da equivalência das ignorâncias que me proponho a pensar algumas práticas curriculares e suas prerrogativas epistemológicas, mesmo que ao fazer uso do exemplo de Rancière, me considere uma mestra ignorante no tema "currículo" a despeito dos quase 30 anos de exercício no magistério, porém procurando ressaltar o fato de como os estudantes de São Paulo nos ensinam sobre os sentidos do currículo quando pensado na perspectiva dos alicerces básicos da cidadania, do acesso e democratização aos bens simbólicos e culturais, sobre a pertença à cidade, seus usos, frequencias e finalmente sobre a luta constante pelo estado de bem-estar social, tema que mesmo para os experts deveria figurar como um debate sempre em aberto aos maiores interessados, os estudantes. A diferença entre a lógica do pedagogo embrutecedor que opera a lógica da transmissão direta do idêntico, com a lógica da emancipação intelectual, nas palavras do Mestre Ignorante:

À esta identidade da causa e do efeito que se encontra no coração da lógica embrutecedora, a lógica da emancipação opõe sua dissociação. Esse é o sentido do paradoxo do mestre ignorante: o aluno aprende do mestre algo que o mestre mesmo desconhece. Aprende como efeito da maestria que lhe obriga a buscar e verificar essa busca. Mas não aprende o saber domestre.

Deste modo, me atenho ao campo de estudos e de trabalho a qual me dedico atualmente que é do ensino das artes, mais especificamente, ao estudo sobre o corpo enquanto instância de produção epistêmica, como realização pedagógica e de comunhão de experiências. Neste sentido, são exemplares o modo como algumas ações performativas que ocuparam as ruas no decorrer do Movimento Ocupa São Paulo, produziram alianças inéditas entre corpo \& imagem, produzindo o 
quechamamosdeencontroinauguralcomocotidianodacidade.Essasatuaçõesredundaramemuma militância poética favorável à aprendizagem em sintonia com a atualidade da cidade e de seus mecanismos, com a retomada de um protagonismo do corpo que a instituição escolar muitas vezes segrega, subtrae, mas que por sua própria força e potência epistêmica reclama o corpo que confere carne e sentido à escola.

Esses experimentos cênicos nos permitem pensar a dimensão pedagógica da performance e de outros trabalhos voltados para uma dramaturgia do corpo/cidade; o que essas proposições nos 170 ensinam? Que entre as dinâmicas entre um corpo vivido e cotidiano, consumido pelo esforço repetitivo e nada inspirador dos estágios de embrutecimento comuns à experiência com/a/na cidade, sobressai a presença de um corpo actual e performativo, socializando os saberes desses processos que alternam a frequência dos atos de ver, escutar, perceber, relacionar-se com a intensidade das ruas, processos que possuem o mérito de favorecer uma atração (que, ao mesmo tempo, poderá desencadear o seu oposto, ou seja, a repulsão) que desestabiliza e impõe uma suspensão nos condicionamentos autômatos dos indivíduos atropelados pela pressa e a anulação da atenção. Talvez seja por esse motivo que os encontros com a rua tenham a oferecer caminhos tão férteis para o trabalho de composição para atores, bailarinos e performers. O Movimento Ocupa nos ensina que que do encontro do corpo com a cidade, o ato de performar fornece generosamente os recursos imagéticos, textuais, sonoros, arquitetônicos, com os quais cada um aspira aos sentidos de uma poética muito particular, porém aberta aos estímulos domundo. 


\section{BIBLIOGRAFIA}

AGAMBEN, Giorgio. O que é o contemporâneo e outros ensaios. Santa Catarina: Argos, 2009 ALLOA, Emmanuel (Org.). Pensar a imagem. BH: Autêntica Editora, 2015

CERTEAU, Michel de. A invenção do cotidiano, volume 1. Petrópolis: Ed. Vozes, 1994

CIDADES REBELDES, vários autores. Carta Maior/BoiTempo Editorial, 2013

ESPIRITO SANTO, Denise. Corpos maquínicos. In: Zonas de contato: usos e abusos de uma estética do corpo (organização). Rio de Janeiro: Outras Letras, 2014

FREIRE, Paulo. Pedagogia do oprimido, 1987 (17 a edição)

http://www.dhnet.org.br/direitos/militantes/paulofreire/paulo_freire_pedagogia_do_oprimido.pdf, acessado em 31/03/2017

MITCHEL, W.J.T. O que as imagens realmente querem? In: ALLOA, Emmanuel (Org.). Pensar a imagem. BH: Autêntica Editora, 2015

RANCIÈRE, Jacques. El espectador emancipado. Buenos Aires: Manantial, 2010

O mestre ignorante. Belo Horizonte: Autêntica, 2007

SPIVAK, Gayatri. Pode o subalterno falar? Belo Horizonte: Ed. UFMG, 2010

TADEU, Tomás. Nós, ciborgues. O corpo elétrico e a dissolução do humano. In: HARAWAY, Donna,

KUNZRU, Hari. Antropologia do ciborgue As vertigens do pós-humano. BH: Autêntica, 2009

TAYLOR, Diane. O arquivo e o repertório. Performance e memória cultural nas Américas. Belo Horizonte:

Ed. UFMG, 2013

\section{Sites e blogs:}

Mídia Ninja - ninja.oximity.com

Jornalistas Livres 